\title{
A multimethod investigation including direct observation of 375 I patient visits to 120 dental offices
}

This article was published in the following Dove Press journal:

Clinical, Cosmetic and Investigational Dentistry

22 May 2010

Number of times this article has been viewed

\author{
Stephen Wotman' \\ Catherine A Demko' \\ Kristin Victoroff' \\ Joseph J Sudano \\ James A Lalumandier \\ 'Department of Community Dentistry, \\ Case Western Reserve University, \\ School of Dental Medicine, Cleveland, \\ $\mathrm{OH}$, USA; ${ }^{2}$ Center of Health Care \\ Research and Policy, Case Western \\ Reserve University, School of \\ Medicine, Cleveland, OH, USA
}

\begin{abstract}
This report defines verbal interactions between practitioners and patients as core activities of dental practice. Trained teams spent four days in 120 Ohio dental practices observing 3751 patient encounters with dentists and hygienists. Direct observation of practice characteristics, procedures performed, and how procedure and nonprocedure time was utilized during patient visits was recorded using a modified Davis Observation Code that classified patient contact time into 24 behavioral categories. Dentist, hygienist, and patient characteristics were gathered by questionnaire. The most common nonprocedure behaviors observed for dentists were chatting, evaluation feedback, history taking, and answering patient questions. Hygienists added preventive counseling. We distinguish between preventive procedures and counseling in actual dental offices that are members of a practice-based research network. Almost a third of the dentist's and half of the hygienist's patient contact time is utilized for nonprocedure behaviors during patient encounters. These interactions may be linked to patient and practitioner satisfaction and effectiveness of self-care instruction.
\end{abstract}

Keywords: dental practice, dental practice core activities, direct observation of dental practice, Dental Davis Observation Code, dentist, hygienist patient behaviors

\section{Background}

Practice-based research networks (PBRNs) were introduced for dental practices in the United States in $1998 .^{1}$ This research tool had been utilized extensively to investigate medical practice. ${ }^{2}$ One of the major contributions of the family medicine PBRN studies was a multimethod approach allowing the comparison of more traditional study methods to findings from a new method devised for direct observation, the Davis Observation Code (DOC). ${ }^{3}$ This work provided new information concerning medical practice, leading to measures to improve both the effectiveness and efficiency of medical care delivery. ${ }^{4,5}$

In 2002 we initiated a landmark multimethod study of dental practice in the Community Research for Oral Wellness Network (CROWN) PBRN in northern Ohio. ${ }^{6}$ Both quantitative and qualitative data concerning procedures performed and patient-practitioner interaction were collected from 120 practices that were each observed for a 3-day period. The resultant database has provided information concerning the content of dental practice, ${ }^{7-9}$ the best methods to obtain specific kinds of information, ${ }^{6,10-12}$ factors influencing the provision of preventive services, ${ }^{13-15}$ and the ability to compare physician and dentist attitudes. ${ }^{16}$

An understanding of what occurs in routine dental practice is emerging from both United States (US) and international studies that utilize different sources of data. Most studies are based on self-reports of dentists collected as part of American 
Dental Association (ADA) surveys ${ }^{17}$ and include evaluation of billing data, ${ }^{18}$ chart audits, ${ }^{19}$ and more recently, the initiation of practice-based clinical trials. ${ }^{20}$ Studies have also incorporated daily logs of dentist activities ${ }^{21}$ and/or have included patient reports of services received for comparison to chart audits. ${ }^{22}$ Each source of information provides a unique view of the practice with its own particular bias. One study has used direct observation to look at the frequency (but not time) of services in a public health practice in Sweden, ${ }^{23}$ but direct observation has not yet been utilized to examine private dental practice. We designed this multi-method study of dental practices, emphasizing direct observation, to simultaneously illuminate several aspects of dental practice and quantify both procedures and the behavioral content of dental visits.

While the performance of technical procedures can be reliably captured from chart review or claims data, ${ }^{24,25}$ the occurrence and characterization of patient-provider interactions requires other methodologies. The effect of communication and interpersonal behaviors between patients and providers has been shown to affect patient satisfaction, perceptions of care, and even health outcomes in medicine., ${ }^{4,5}$

While dentistry has a rich literature on patient anxiety, fear, and phobias, much less is known about the routine interactions during the dental visit, which by virtue of their pervasiveness could exert similar effects on oral health outcomes. Direct observation of a large number of patient visits offers the opportunity to collect this information, providing a fuller description of patient visits and complementing the quantitative data on frequency and timing of observed behaviors. The link between procedure-based interactions and verbal interactions is not well characterized and such knowledge will lay the foundation for oral health research on patient and provider behavior change, effects of communication on patient self-care and adherence, and interventions to improve communication and patient-centered care.

Recently, two important developments in health services research have been utilized for dental practice. These developments are the formation of dental practice-based research networks ${ }^{20,26}$ and the adaptation of a standardized instrument for studying medical practice, the $\mathrm{DOC}^{3}$ for use in dental practice. This new instrument is used to quantify dentist and hygienist behaviors as components of actual practice. Direct observation allows for additional qualitative assessment of the interaction, a technique that has been extensively developed and tested by Crabtree et al. ${ }^{27}$ The application of these new methods is important to the understanding of dental practice both internationally and in the United States.
For this report, we provide evidence that counseling and verbal interaction of both dentists and hygienists with patients can be defined and quantified (using the Dental DOC described in the data instruments section below) so that they can be included as part of the core activities of dental practice. For the most part, previous studies have been unable to define and quantify these behaviors.

\section{Materials and methods}

This study was modified for dental practices from the study of family medicine practices conducted by Stange et al. ${ }^{2}$ The family medicine group participated in the dental study providing practical advice, access to their methods and instruments as well as contributions to this and other publications. This is one of a series of papers utilizing data from this study of dental practice. This paper expands the description of methodology presented by Demko et al concerning concordance of the methods used in this study. ${ }^{6}$ The current paper includes this information in order to provide a more complete description for investigators who might want to repeat this study with other PBRNs. Statements from the Demko paper are quoted directly while some of the methods presented in the Stange paper are presented in their dental context.

\section{Sites and subjects}

The participating practices in this study were members of the CROWN practice-based research network located in 18 counties of northern Ohio. ${ }^{1}$ In 2004, 2500 dentists on the State licensure list in northern Ohio were asked to participate in a direct observation study. One hundred sixty-six dentists responded positively. Dental specialists, full-time academic dentists, and retired dentists were excluded. Based on power calculations for testing the main hypotheses regarding preventive service delivery, 120 practices were selected for the multimethod study. Consecutive patients seen in each office by a dentist and hygienist during a 3-day period between June 2004 and September 2005 were enrolled after giving informed consent. Chart and billing data abstraction occurred on a fourth day in each office. Dentists who declined to participate, but completed the recruitment survey $(n=306)$ were similar to study participants in age, sex, professional experience, and practice patterns, but were more likely to not employ a hygienist in their office.

\section{Data instruments}

The central data instrument for the Direct Observation Study (DOS) is the Dental DOC, a modified version of the Davis Observation Code that classifies patient contact 
time into 24 categories to measure time utilization during the patient visit. The DOC was modified from the original Callahan and Bertrakis version ${ }^{3}$ utilized for family medicine practice by Stange $^{2}$ to reflect behaviors and definitions specific to dental practice. With the assistance of Drs Callahan and Stange, categories such as comfort, structured interaction, preventive service, and preventive counseling were redefined to reflect the distinct nature of the dental encounter. The definitions were refined through focus group meetings and discussions among the observers and research team reflecting years of practice background of the research hygienists. The DOC definitions are included in the Appendix.

To complete the Dental DOC, the hygienist-researchers recorded any of the 24 behaviors that were observed during the dental visit at 30-second intervals directly into a tablet computer using a stylus. A full description of direct data entry using the tablet recorder is reported elsewhere. ${ }^{12}$ The Dental DOC measured the length of the dentist- or hygienist-patient contact time for each patient visit.

At the conclusion of the visit, directly observed procedures were recorded on the tablet computer using the post visit checklist (PVC), a listing of 65 usual services. Thus, the observer could record the amount of time spent on procedures, distinct from the checklist amount of time spent on verbal, nonprocedure behaviors. Information concerning patient demographics and major reasons for the visit was also included.

To complete the chart audit (CA), hygienist-researchers reviewed the services noted on the chart for the observed visit. The chart audit form was identical to the PVC to facilitate comparison to the observed services. The $\mathrm{CA}$ also recorded information relating to medical history, risk for dental caries, periodontal disease, or oral cancer, insurance status, and whether the patient was a new, emergency, or an established patient. Patients who had been seen in the practice during the last three years were considered 'established patients'.

Billing codes and charges were retrieved from the billing records for each observed visit. The billing codes were then translated to services using the Common Dental Terminology codes, versions 4 and 5 (CDT-4 and CDT-5) and compared to the services specified on both the PVC and the CA. Both the CA and billing data collection occurred on the fourth day of the office visit after direct observation had been completed.

The patient survey (PS) collected information on patient age, sex, race, education, income levels, and marital status. Survey items included the patient's reason for the visit, perceived oral and general health status, whether particular services were provided during the observed visit, and if the patient was referred to another medical or dental practitioner. Patient satisfaction, for the current report, was assessed using a single measure. Patients who did not have time to complete the questionnaire at the visit were given a confidential pre-paid envelope to be mailed to the study office. Parents or guardians completed questionnaires for children aged under 13 years while patients aged 13 to 17 years usually completed the questionnaire themselves with help from a parent or guardian. Only $7.5 \%$ of all participating patients did not complete a questionnaire.

Practice-level characteristics were collected by the research team using the practice environment checklist (PEC), which included items concerning practice type, location, physical attributes of the office, number and types of personnel, and office operations based on direct observation and interviews with office personnel by the research hygienists. The purpose of this checklist was to identify practice factors that potentially affect the delivery of preventive or other services. Several patient-level characteristics were aggregated from information on the patient surveys, chart audits, and direct observation data from the DOC and PVC to contribute to practice profiles. Finally, dentist and office hygienist (RHO) characteristics were gathered by provider self-administered questionnaires. These surveys collected information on personal characteristics, professional training, career satisfaction, attitudes about preventive services, and self-report of services provided.

The observations were enhanced by qualitative data notes recorded for most patient encounter observations. These notes or 'brief jottings" ${ }^{77}$ were dictated or typed into the tablet computer by the observers immediately after each day's visit. This voluminous database was organized using NVivo software and was used to enrich the quantitative observation data as well as to stimulate hypothesis formulation. ${ }^{2}$

\section{Data collection, training, and inter-rater reliability}

Before the start of the study, four hygienist-researchers were extensively trained in the use of all research instruments and data collection techniques. All four observers remained for the entire data collection period. In addition, two patient coordinators were trained to obtain informed consent and make observations about the practice environment. The observers were organized into two, three-member teams, each comprised of two hygienist-researchers and one patient coordinator. One observer followed the dentist and the other observed the hygienist in the office. Where multiple dentists 
and/or hygienists were present, the team selected one dentist and one hygienist to follow. Where the same dentist was not present on the three days of observation, a substitute dentist was chosen and regarded as an independent dentist in the practice.

All data, except that obtained by survey, were entered directly into tablet computers utilizing SNAP Software (Version 7; Boston, MA) ${ }^{28}$ Survey data was scanned into SNAP and converted to SPSS files (SPSS Inc, version 13.0, Chicago, IL, USA 2004) for data management and analysis. ${ }^{29}$ "'Observer variability was minimized by repeated standardization of observers through the use of videotapes of routine dental encounters in practice situations. For inter-rater reliability, the four hygienists watched videotaped patient-dentist encounters together while individually scoring these encounters using a pre-set list of behaviors adapted from the DOC. ${ }^{3}$ Thirteen standardizations were conducted throughout the study period, in addition to monthly debriefing sessions to discuss ongoing data collection issues and augment the field notes. We calculated multirater kappa coefficients from thirteen standardization sessions, totaling 181 minutes, using STATA (release 8; STATA Corporation, College Station, TX). ${ }^{30}$ Kappa coefficients for codes common to both the DOC and PVC were: treatment planning $=0.74$, oral exam $=0.92$, fluoride treatments and sealants combined as preventive procedures $=$ 0.83 , oral health instruction $=0.77$, and oral cancer exam $=$ 0.69. Kappa coefficients for verbal interaction codes were: chatting $=0.79$, comfort $=0.67$, history taking $=0.82$, systemic health $=0.83$, oral preventive counseling $=0.77$, and patient questions $=0.79$. Reliability of defining and recognizing standard dental procedures (eg, extractions, amalgams, crowns/bridges) was assured by both the ability to retain the experienced observer hygienists throughout the entire study. Discussions of definitions were held at each debriefing and standardization session. Intra-rater reliability was established by repeating observations on videotape or chart audits during debriefing sessions. Further, inter-rater reliability of items abstracted from chart audits was determined by having all six team members perform chart abstraction on the same set of charts (multi-rater kappa across all charted items $=0.868) "{ }^{6}{ }^{6}$

Validity of observations was established by in-depth discussions among the four observers of definitions used for the Dental DOC and for procedures recorded from the CA and PVC. This 'reconciliation of definitions' was addressed at the monthly meetings. Each of the hygienist-researchers had at least ten years of experience in a dental office.
Substantial efforts were undertaken to minimize the possibility of the presence of the observation team influencing practitioner or patient behaviors (Hawthorne effect). ${ }^{31}$ Dentists and staff followed usual procedures. While practitioners and staff were told that the study would observe 'what dentists do', no specific questions or hypotheses were shared with practitioners, staff, or patients. Observation of patients seen on the regular schedule made it difficult for practitioners to spend more time or provide more services than usual without disrupting the schedule. Observers were instructed to avoid eye contact between the observer and practitioner or patient. The vast majority of dentists, hygienists, and patients reported that the presence of a hygienist observer did not change their behavior during the observed visits (unpublished data). ${ }^{2}$

Analyses for this report included calculation of percents, ranges, means, and standard deviations, depending on the variable being measured. To measure frequency of behaviors, we calculated the percent of visits in which the behaviors or procedures were observed during the dentist and hygiene visits as recorded on the DOC or PVC. From the DOC, we calculated the total patient contact time per visit (ie, the time the dental provider was in the room with the patient) from the total of the observed 30 -second intervals and across the visits we calculated the mean length of patient contact time. For time spent on the individual DOC codes, mean percent of time was calculated from the number of 30 -second intervals divided by the total visit intervals, but this likely overestimates the percent time, since the occurrence of the behavior or communication did not necessarily extend the full 30 seconds. This information allowed for an estimate of the time and frequency devoted to individual behaviors.

Informed consent was obtained from the dentists, hygienists and patients by the patient coordinator. The study was approved by the Case Western Reserve University (CWRU) Institutional Review Board.

\section{Results}

Table 1 provides characteristics of the participating practices, dentists, and hygienists. The majority of the 120 practices (63\%) were solo practices, with the other one-third comprised mostly of two- and three-dentist groups. Two-thirds of practices were in suburban locations with the other onethird equally divided between urban and rural locations. This compares with national data compiled by the ADA showing that $62.9 \%$ of dentists are in solo practice. ${ }^{32,33}$

In our sample, $95 \%$ of the practices included a dental hygienist, considerably higher than the national average 
Table I Practice and provider characteristics

\begin{tabular}{|c|c|c|}
\hline Practice characteristics & Percent & \\
\hline \multicolumn{3}{|l|}{$\begin{array}{l}\text { Source of data: environmental } \\
\text { checklist }(n=\mid 20)\end{array}$} \\
\hline \multicolumn{3}{|l|}{ Method used: direct observation } \\
\hline \multicolumn{3}{|l|}{ Practice size } \\
\hline Solo practitioner & 63.0 & \\
\hline Group ( 3 or more dentists) & 13.8 & \\
\hline \multicolumn{3}{|l|}{ Practice location } \\
\hline Suburban & 67.5 & \\
\hline Urban & 15.8 & \\
\hline Rural & 16.7 & \\
\hline Practice employs RDH & 94.0 & \\
\hline \multicolumn{3}{|l|}{ Practice case mix } \\
\hline Primary & $55.2 \pm 16.4$ & \\
\hline Rehabilitative & $28.1 \pm 15.3$ & \\
\hline Acute (emergency) & $16.8 \pm 10.1$ & \\
\hline Patients seen per day & $14.7 \pm 5.8$ & \\
\hline Educational materials present & 98.3 & \\
\hline Provider characteristics & DDS & RDH \\
\hline $\begin{array}{l}\text { Source of data: dentist and hygie } \\
\text { survey } \\
\text { Dentist }(n=125) \text { and hygienists } \\
(n=134) \text { Method used: self-rep }\end{array}$ & & \\
\hline Age (Mean \pm SD) & $49.0 \pm 9.7$ & $40.8 \pm 9.9$ \\
\hline \multicolumn{3}{|l|}{$\operatorname{Sex}(\%)$} \\
\hline Male & 83 & I \\
\hline Female & 17 & 99 \\
\hline \multicolumn{3}{|l|}{ Race (\%) } \\
\hline African American & 4 & 1 \\
\hline Caucasian & 93 & 99 \\
\hline \multicolumn{3}{|l|}{ Days/Week at practice (\%) } \\
\hline 3 days or less & 13.6 & 44.6 \\
\hline 4 days & 62.4 & 41.5 \\
\hline 5 or more & 24.0 & 13.8 \\
\hline General practice residency & 39.2 & \\
\hline
\end{tabular}

Abbreviations: DDS, doctor of dental surgery; $\mathrm{RDH}$, registered dental hygenist $\mathrm{SD}$, standard deviation.

of $75.3 \%{ }^{31}$ The most prevalent clinical personnel, after dentists and hygienists in these practices, were dental assistants (96.5\%), and expanded function dental assistants (EFDA) (27\%). Practices varied widely in the balance among acute (emergency), primary, and rehabilitative care provided. ${ }^{34}$ On average, about half $(55.2 \%)$ of the observed patients seen by the dentist received some type of primary care service, while $28 \%$ received a rehabilitative procedure. Seven offices had no emergency visits during the observation period, while only two offices did not perform a rehabilitative procedure. Rehabilitative care included full and partial denture and all crown and bridge services; emergency care included treatment for pain, trauma, or other emergencies presented by patients; and primary care included all other services.

Participating dentists were similar in distribution to all Ohio dentists in terms of age (49.0 \pm 9.7 years) and years in practice $(22.1 \pm 9.8$ years $)$, while female dentists were slightly over-represented in the study $(16.8 \%)$ compared to the state $(12 \%) .{ }^{6}$ Overall, the sample was comprised of experienced practitioners, as only $15 \%$ had been in practice less than 10 years. Five African American dentists participated in the study and many dentists had completed a general practice residency (39\%). Our sample's proportion of female dentists is similar to the percent of female practitioners in the national work force $(18.3 \%)^{35}$ and included more than twice the national average of practicing dentists who have completed graduate practice residencies (16.8\%) ${ }^{32,33}$ Most dentists were found to work four days a week (62.4\%), while equal proportions of hygienists worked less than 4 days a week (43.2\%) or 4 days $(40.3 \%)$.

Of the 4547 eligible patients who appeared for care during the observation days, 3803 agreed to be observed for a consent rate of $83 \%$. Reasons for ineligibility were minors without an adult for consent and patients that dentists asked us not to approach $(n=84)$. Approximately $7 \%$ of patients were missed $(n=330)$ due to time constraints with only one patient coordinator available in the waiting room, $8 \%$ of patients declined $(n=344)$ and 70 patients consented but were not observed, generally because they changed their mind before the appointment started. Gender distribution of those who declined was similar to observed patients ( $43 \%$ were males), but were more likely to be greater than age 65. 'Not interested' or 'no reason' accounted for most refusals, while concerns with privacy, in too much pain, or too nervous about visit were the next most likely reasons given for declining.

Table 2 describes the characteristics of the observed patients and visits. The 3751 office visits included 3697 unique patients. Patient surveys were completed by 3423 patients, a $92.5 \%$ return rate. More female $(58.3 \%)$ than male $(41.7 \%)$ patients were observed as is generally reported in the dental literature. Only $37 \%$ of patients had a college degree or better and $42 \%$ reported incomes of less than US $\$ 55,000$ a year.

Characteristics of the 2212 dentist and 1539 hygienist visits are also shown in Table 2 . The mean length of observed patient contact time for dentist visits was $25.7 \pm 20.4$ minutes and $36.5 \pm 12.8$ minutes for hygiene visits. The time 
Table 2 Patient and visit characteristics

\begin{tabular}{|c|c|}
\hline Patient characteristics & Percent \\
\hline \multicolumn{2}{|l|}{ Source of data: patient survey $(n=3423)$} \\
\hline \multicolumn{2}{|l|}{ Method used: self-report } \\
\hline Age (years, mean $\pm S D$ ) & $45.2 \pm 21.3$ \\
\hline Male & 41.7 \\
\hline \multicolumn{2}{|l|}{ Race } \\
\hline Caucasian & 89.4 \\
\hline African American & 8.7 \\
\hline Other & 1.9 \\
\hline \multicolumn{2}{|l|}{ Education } \\
\hline Less than 12 years & 17.2 \\
\hline High school/GED/some college & 45.0 \\
\hline College graduate + & 27.7 \\
\hline \multicolumn{2}{|l|}{ Household income } \\
\hline Less than $\$ 34,999$ & 25.3 \\
\hline$\$ 35,000-\$ 54,999$ & 17.4 \\
\hline$\$ 55,000+$ & 40.5 \\
\hline No answer & 16.8 \\
\hline Current tobacco users & 15.3 \\
\hline Any alcohol use & 47.5 \\
\hline Patient satisfaction (very satisfied) & 71.4 \\
\hline \multicolumn{2}{|l|}{ Visit characteristics } \\
\hline \multicolumn{2}{|l|}{ Source of data: dental and hygiene DOC } \\
\hline \multicolumn{2}{|l|}{ Dentist DOC $(n=2212)$} \\
\hline \multicolumn{2}{|l|}{ Hygiene DOC $(n=1539)$} \\
\hline \multicolumn{2}{|l|}{ Method used: direct observation } \\
\hline \multicolumn{2}{|c|}{ Patient contact time (ninutes, mean $\pm S D$ ) } \\
\hline DDS & $25.7 \pm 20.4$ \\
\hline $\mathrm{RDH}$ & $36.5 \pm 12.8$ \\
\hline \multicolumn{2}{|l|}{ Percent of time spent on procedures } \\
\hline DDS & $65.8 \pm 23.2$ \\
\hline $\mathrm{RDH}$ & $55.6 \pm 15.6$ \\
\hline \multicolumn{2}{|c|}{ Reason for visit (\% of total observed visits) } \\
\hline Routine (ongoing care) & 46.1 \\
\hline Recall & 32.4 \\
\hline Emergency & 8.1 \\
\hline New patient exam & 5.9 \\
\hline
\end{tabular}

Abbreviations: DOC, Davis Observation codes; DDS, doctor of dental surgery; $\mathrm{RDH}$, registered dental hygenist; SD, standard deviation.

indicated for the hygiene visit includes 3 to 5 minutes of dentist time when the dentist enters the hygienist's operatory. The most common reasons for visits include routine care, prophylaxis, and recall. Most patients were very satisfied with their visit (71.4\%) while an additional $26 \%$ reported being satisfied.

Table 3 provides examples from the field notes for the nine most prevalent non-procedure behaviors in Figure 1. Some examples depict global statements describing the provider, while others provide insight to the content and delivery of the communication. Thematic analysis of these qualitative statements was completed for the Comfort code ${ }^{3}$ and is underway for several other codes. The median number of intervals in which these behaviors occurred is also shown in Table 3.

Because the DOC was designed to permit the coding of concomitant procedure and nonprocedure behaviors, combinations of procedures and verbal interactions can be analyzed as well as ordered. In the dentists' visits, for example, only $29 \%$ of all oral preventive counseling is provided during an interval when a procedure was being performed. Among hygiene visits, 54\% of oral preventive counseling (OPC) is delivered during a procedure (ie, during prophys). Thus, although only $20 \%$ of dentist visits included preventive counseling, most of it occurred independently of procedures. The distribution of the ten most common procedures performed by dentists as recorded on the PVC is shown in Figure 1.

An oral exam was the most common single procedure, followed by placing composites (one or more white fillings), placing crowns, and providing preventive services such as fluoride treatments, sealants, or an oral cancer exam. When these procedures are grouped into five general procedural categories, their order of prevalence is restorative, diagnostic, prosthodontic, preventive, and oral surgery services. For hygienists the single most common procedure was prophylaxis (95\% of visits), followed by oral exams (94\%), radiographs (43\%), and then all other preventive services (data not shown). From the time recorded on the Dental DOC, we calculated that procedures filled an average of $65 \%$ of patient contact time for the dentist and $56 \%$ for the hygienist.

Figures 2 and 3 report two separate measures of behaviors recorded on the Dental DOC. These are the frequency and time spent by dentists and hygienists on behaviors during non-procedure time. The Dental DOC permitted recording individual non-procedure behaviors such as oral health counseling topics, patient questions, and chatting. Figure 2 describes the frequency of the most common non-procedure behaviors observed during patient visits. The most frequent behaviors observed for dentists were chatting, evaluation feedback, history taking, and answering patient questions. The most common behaviors for hygienists were similar and also included preventive counseling. Except for chatting, patient questions, and providing comfort, these verbal interactions with patients occured far more often during the hygiene visit than during the dental visit; discussions about systemic health issues and preventive counseling for general 
Table 3 Observed behavior codes with qualitative notes

\begin{tabular}{|c|c|c|c|}
\hline $\begin{array}{l}\text { Observed behaviors }^{\mathrm{a}} \\
\text { (DOC codes) }\end{array}$ & Examples of field notes & $\begin{array}{l}\text { Number of 30-se } \\
\text { Median (range) }\end{array}$ & tervals per visit \\
\hline CH Chatting & $\begin{array}{l}\text { When the Dr came in...he would tell them it was so good } \\
\text { to see them, he would ask about what was going an in their lives. } \\
\text { He sits down and talks to each patient for about five minutes before } \\
\text { he does anything. He talks about the trip he went on, asks what they are } \\
\text { doing, personal things, life things. Not dentistry, but about their life. }\end{array}$ & $\begin{array}{l}\text { DDS } \\
5 \\
(0,93)\end{array}$ & $\begin{array}{l}\text { RDH } \\
\text { II } \\
(0,92)\end{array}$ \\
\hline EF Evaluation feedback & $\begin{array}{l}\text { The RDH would then ask the patients what they thought of their } \\
\text { [periodontal charting] numbers. She would give them feedback } \\
\text { and she would then go over oral hygiene instruction and } \\
\text { discuss how they could improve things....she brought up } \\
\text { oral hygiene and home care and used negative framing. } \\
\text { She told him they had to re-seal one of his teeth because } \\
\text { "if they didn't he'd get cavities and he didn't want that." She said } \\
\text { "you need to brush better or when they take your braces off } \\
\text { you'll have white spots all over your teeth." }\end{array}$ & $\begin{array}{l}3 \\
(0,33)\end{array}$ & $\begin{array}{l}3 \\
(0,19)\end{array}$ \\
\hline HT History taking & $\begin{array}{l}\text { The dentist also spends a lot of time trying to gather a lot } \\
\text { of information from her patients; if they have a complaint; } \\
\text { she spends a lot of time listening to them. }\end{array}$ & $\begin{array}{l}\text { I } \\
(0,25)\end{array}$ & $\begin{array}{l}2 \\
(0,17)\end{array}$ \\
\hline PQ Patient questions & $\begin{array}{l}\text { He took the time to answer patient questions thoroughly } \\
\text { and educated them quite a bit about dental procedures. He gave } \\
\text { patients feedback on how their gums look to support the importance } \\
\text { of that and the hygienist's role. }\end{array}$ & $\begin{array}{l}\text { I } \\
(0,39)\end{array}$ & $\begin{array}{l}\text { I } \\
(0,14)\end{array}$ \\
\hline CC Comfort & $\begin{array}{l}\text { He wanted to ensure her comfort, while pulling her tooth... } \\
\text { she gave a slight moan, he stopped immediately, added more anesthetic } \\
\text { and sat right with her for a couple minutes talking with her before } \\
\text { attempting to painlessly remove it. }\end{array}$ & $\begin{array}{l}0 \\
(0,25)\end{array}$ & $\begin{array}{l}0 \\
(0,2 I)\end{array}$ \\
\hline SH Systemic health & $\begin{array}{l}\text { The dentist reviewed every medical history and update. He would } \\
\text { sit down with the patient and review the medical history first } \\
\text { thing and would say "Oh, I see you've been on Lipitor }{ }^{\circledast} \text { and that's } \\
\text { new, how's that going?" } \\
\text { They updated blood pressure on patients with a history of high } \\
\text { blood pressure. }\end{array}$ & $\begin{array}{l}0 \\
(0,17)\end{array}$ & $\begin{array}{l}\text { I } \\
(0,17)\end{array}$ \\
\hline $\begin{array}{l}\text { OPC Oral preventive } \\
\text { counseling }\end{array}$ & $\begin{array}{l}\text { This RDH talked to her a lot about the effects of smoking on } \\
\text { periodontal disease and pop and sugar on tooth decay...she educates } \\
\text { patients by talking at their level, treats them like people, and doesn't talk } \\
\text { down to them. She gave lots of lessons throughout the entire process, } \\
\text { showing the patient how to brush and floss, as well as telling } \\
\text { them why they needed to do this. }\end{array}$ & $\begin{array}{l}0 \\
(0,17)\end{array}$ & $\begin{array}{l}3 \\
(0,56)\end{array}$ \\
\hline $\begin{array}{l}\text { SM Smoking counseling } \\
\text { NU Nutrition counseling }\end{array}$ & $\begin{array}{l}\text { The office is taking the time to find out about any tobacco habit } \\
\text { and dietary habits that may affect oral health gum, hard candy, coffee, or } \\
\text { chewing ice. The Dr is very interested in smoking cessation he has } \\
\text { a lot of pamphlets about smoking and the RDH took some courses } \\
\text { and counsels patients. }\end{array}$ & $\begin{array}{l}0 \\
(0,5) \\
(0,6)\end{array}$ & $\begin{array}{l}0 \\
(0,14) \\
(0,23)\end{array}$ \\
\hline
\end{tabular}

Note: ${ }^{a}$ Code definitions are in Appendix.

Abbreviations: DOC, Davis Observation Codes; DDS, doctor of dental surgery; RDH, registered dental hygenist.

oral health or specific topics occurred most often during the hygiene visit.

Figure 3 reports the percent of the patient contact intervals that included the nonprocedure behaviors, calculated from visits in which the behavior occurred. Chatting, preventive counseling, and patient questions account for a similar proportion of intervals by both the dentist and the hygienist.
Comfort accounts for a greater proportion of the hygienists' time. All other behaviors are present in a greater proportion of the dentists' visits when compared to the hygienist. An example of the different perspective provided by each measure (frequency versus \% of time) is revealed by the data for preventive counseling. The frequency of preventive counseling is four times greater during the hygiene visit as 


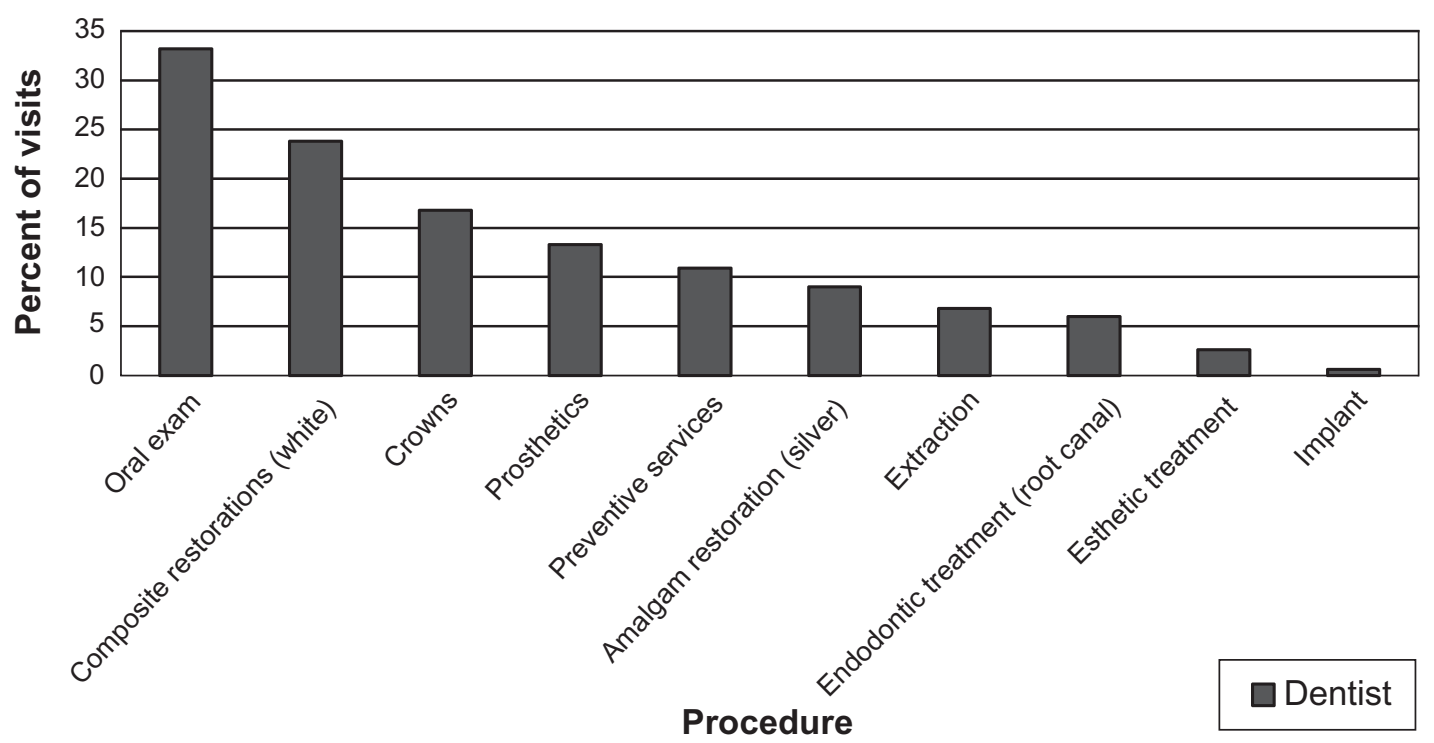

Figure I Distribution of the ten most common procedures performed by dentists as directly observed during 2212 visits.

during the dentist visit (Figure 2). However, the percent time spent on preventive counseling behavior, when it occurs, is similar for both the dentist and hygienist.

\section{Discussion}

The multimethod approach emphasizing direct observation utilized for this study together with the availability of a practice-based research network provides a new opportunity to identify the core activities of dental practice. The utilization of the Dental DOC to quantify nonprocedure behaviors of dentists and hygienists adds a new dimension to the view of essential activities during patient care.

This multimethod study confirms and extends the feasibility of carrying out direct observation study (DOS) in the confines of busy dental offices. ${ }^{1}$ The use of the direct observation methodology to collect both quantitative and qualitative data and combine it with data from the more traditional collection methods of self-report and chart abstraction now allows for the construction of more detailed and enriched profiles of dental practice and provider-patient interactions.

In this study, the presence of data collection teams minimized the time practitioners needed to devote to the study. The fact that data was collected by the observation team, thus minimally disturbing the routine of the practice, may have encouraged practitioner participation despite the potential intrusiveness of direct observation. The fact that dentists volunteered their offices without compensation is indicative of the interest that some dentists have in participating in research that will contribute to professional knowledge.

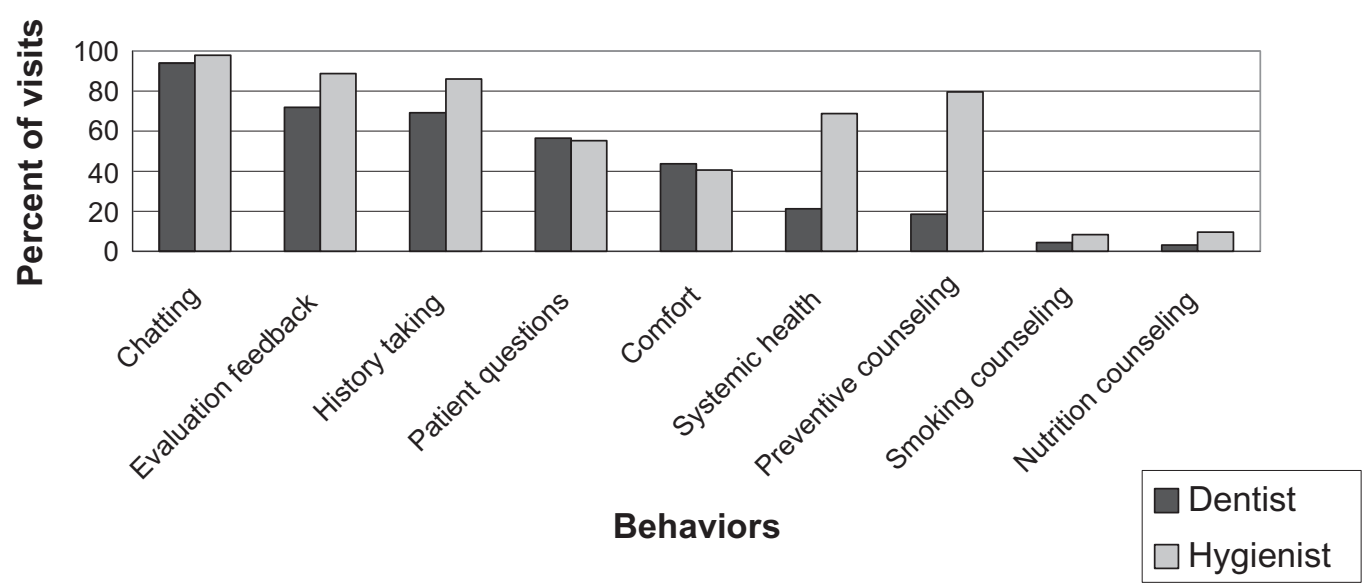

Figure 2 Frequency of the most common nonprocedure Davis Observation Code behaviors observed during 375 I patient visits as recorded on the Dental Davis Observation Code. 


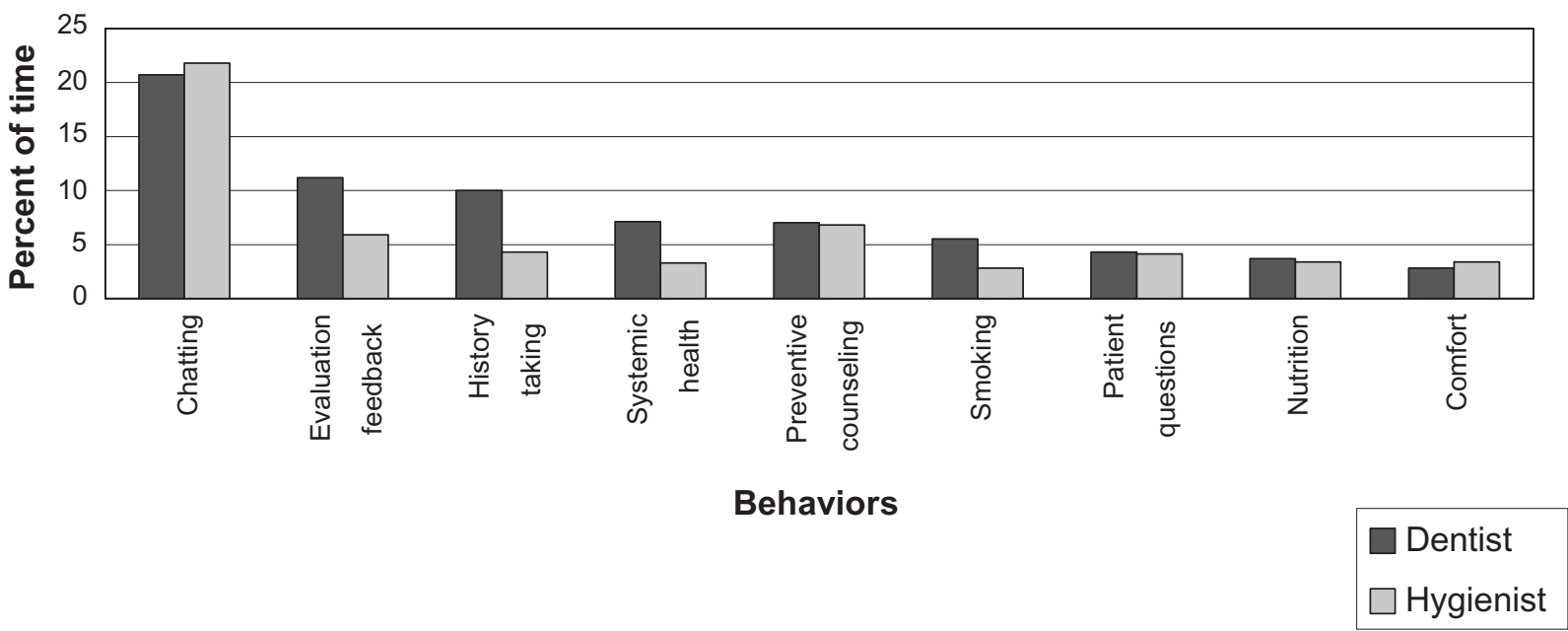

Figure 3 Percent of the patient contact time spent by dentists and hygienists performing the nonprocedure Davis Observation Code behaviors, calculated from visits in which the behavior occurred.

The sample of practices suffers from the same limitations that all practice-based network research exhibits: participants are volunteers and not randomly selected; regional geographic areas may have particular practice biases; and graduates of one particular dental school may predominate in the sample. These population-related shortcomings should be mitigated by the size and diversity of the patient sample, the geographically diverse area from which the sample was drawn, the comprehensive nature of the data collected, and the potential repetition of this study in populations in other geographic locations. Observing a large number of patient visits in many offices provides the opportunity to see and record every stage of dental treatment provided by the dentist or hygienist, thus mitigating bias concerned with the absence of longitudinal observations of the same patient.

Core activities of dental practice have been explored by several investigators and have focused on delivery of procedures. The ADA routinely releases reports describing various aspects of dental practice based on a large number of dentists self-reporting the provision of services. ${ }^{17}$ In Australia, Brennan and colleagues used the distribution of procedures, based on self-reports, to categorize practices. ${ }^{36}$ Brennan proposed practice styles based on clusters of procedures. His defined styles do not include any information about the nonprocedure behaviors of practitioners. Our study provides evidence for the broad scope of verbal interactions that occur during the dental visit and that these behaviors can be reliably recognized, quantified, and occur with sufficient frequency and time to be considered additional core characteristics of practice.

We also speculate that the distribution of practitioner nonprocedure behaviors may be important elements in the differentiation of practice styles and values in different national environments. We expect that both procedure and nonprocedure behaviors will vary in different regions of the US and also hypothesize that these nonprocedure behaviors will reflect characteristics manifest in patient-dentist interactions in different national settings. This possibility enhances the utility of the use of the Dental DOC in international studies of dental practice.

The core nonprocedure behaviors utilized by both the dentist and hygienist all represent patient-practitioner interaction. The question arises whether these activities maintain or promote health and treat disease. In studies of family medical practice, chatting and evaluation feedback are associated with patient satisfaction. ${ }^{4}$ Other interpersonal codes are related to effects of gender of practitioners on care ${ }^{37}$ or whether gender of the patient affects care given. The effect of different styles of practice ${ }^{5}$ characterized by analysis of practitioner behavior or practice setting ${ }^{38,39}$ is also reported. While similar correlations have not yet been done for dental practice it is tempting to speculate that responding to patient questions and the provision of comfort could not only be associated with patient satisfaction and retention in the practice, but also with compliance with oral health instruction. The predominance of prevention during the hygiene visit and its relative absence during interactions with the dentist is probably of great importance.

Dentistry, for the most part, remains a cottage industry. Individual dentists practice in individual offices making decisions in relative isolation. Dentists are not usually socialized into the hospital culture. As a result, the uses of nonprocedure time, (the interactions with patients not learned 
in dental school) are developed by each individual dentist or dental practice and may be subject to wide variation. This study demonstrates that despite the variation in method and content, the major issues addressed by the dental team in these nonprocedure time periods were observed at all offices. We speculate that these issues may be perceived by patients in different ways than the dentist imagines. ${ }^{14}$ The provision of a taxonomy (Appendix) for these functions that reflect what is also done in medicine provides a field of reference for this new knowledge about dental practice. ${ }^{3}$ The establishment of baseline data for these interactions allows more accurate measure of interventions for dental practices that seek to improve functions dependent on patient interaction such as preventive interventions, ${ }^{13}$ the incorporation of patient approaches dependent on risk (especially caries risk), and the ability to compare methodologies commonly used in dental practice research concerning patient interaction. ${ }^{6}$

Substantial findings from this study have already been published or presented at national meetings. This study comparing methods for the investigation of dental practice and published results suggests that studies based on surveys, chart audits, and billing records need to adjust data based on the differences reported for direct observation. Billing data and chart audits understate services while surveys tend to overstate the same services. ${ }^{6}$ The focus of the hygienist on preventive services is confirmed by this study and the key element in offices that emphasizes prevention seems to be the activity of the dentist. ${ }^{13}$ The value of the nonprocedure services provided in the dental office is emphasized by a published analysis of how comfort is provided to patients based on the qualitative portion of this analysis. ${ }^{7}$

The comprehensive methodology utilized in this study makes possible the identification of core activities based on observation of the real world of dental practice available in practice-based research networks. The simultaneous use of multimethods in conjunction with direct observation raises questions concerning how validity and reliability of existing practice study methods can be improved, as well as issues of the effect of practitioner-patient interaction on practice outcomes.

\section{Acknowledgments}

The authors wish to thank members of the Department of Family Medicine of the School of Medicine, Case Western University. This study was inspired by the multi-method study of physicians conducted in that department. Dr Kurt Stange, Dr Susan Flocke, and Dr Stephen Zyzanski, who were investigators in the Family Medicine Study, served as our co-investigators for this NIDCR-funded Direct Observation of Dental Practice Study (R01DE015171). They provided advice based on their experience on design, data collection, data handling and analysis, and they have reviewed drafts of papers. They also allowed us to troubleshoot based on their experience with direct observation of Family Medical Practice. ${ }^{2}$

We would also like to thank the practice observers Marian Kofford, Kate Mingus RDH, Gail Perry RDH, Marlene Rodriguez RDH, Marianne Scherry RDH, Becky Slivka, and Joy Wiedemann as well as the National Advisory Committee consisting of Howard Bailit DDS, PhD, Duncan Neuhauser PhD, Edward Callahan PhD, Randall Cebul MD, $\mathrm{PhD}$, Benjamin Crabtree PhD, and Donna Homenko RDH, $\mathrm{PhD}$ who provided periodic review and oversight. Finally we acknowledge the dentists, hygienists, patients, and personnel of the 120 practices who graciously allowed us to observe them in action for this study.

\section{Disclosures}

The authors report no conflict of interest in this work.

\section{References}

1. Wotman S, Lalumandier J, Nelson S, Stange K. Implications for dental education of a dental school-initiated practice research network. J Dent Educ. 2001;65(8):751-759.

2. Stange K, Zyzanski S, Jaen C, et al. Illuminating the 'black box'. A description of 4454 patient visits to 138 family physicians. J Fam Pract. 1998;46(5):377-389.

3. Callahan E, Bertakis K. Development and validation of the Davis Observation Code. Fam Med. 1991;23(1):19-24.

4. Gross D, Zyzanski S, Borawski E, Cebul R, Stange K. Patient satisfaction with time spent with their physician. J Fam Pract. 1998;47(2):133-137.

5. Flocke S, Miller W, Crabtree B. Relationships between physician practice style, patient satisfaction, and attributes of primary care. $J$ Fam Pract. 2002;51(10):835-840.

6. Demko C, Victoroff K, Wotman S. Concordance of chart and billing data with direct observation in dental practice. Community Dent Oral Epidemiol. 2008;36(5):466-474.

7. Abbe M, Sudano J, Demko C, et al. Revisiting Comfort: Strategies Observed in the Direct Observation Study. General Dentistr. 2007;55:420-425.

8. Victoroff KZ, Demko CA, Lalumandier J, et al. Direct observation study: observed type and frequency of services provided. JDR. Vol. 85 Special issue A. 2006; Orlando.

9. Williams K, Demko C, Lalumandier J, Wotman S. Caring for AfricanAmerican patients in private practice. JADA. 2008;139:1218-1226.

10. Slivka M, Deko CA, Sawyer D, Smith D, Wotman S. Weekly return study of oral lesions in the dental office. JDR. Vol 85 Special issue A. 2006; Orlando.

11. Demko CA, Zyzanski S, Wotman S. Intra-cluster correlations from a practice based observational study of dental care. JDR. Vol 88 Special issue A. 2009; Miami Beach.

12. Sudano JJ Jr, Kofford B, Wotman S. Using tablet PC's in dental practice research: technology, cost savings, and direct data entry "on the go". J Public Health Dent. 2005;65(4):244-245. 
13. Demko CA, Lalumandier J, Sudano J, Williams K, Abbe M, Wotman S Direct observation of prevention counseling and procedures in dental offices. JDR. Vol. 85 Special issue A. 2006; Orlando.

14. Demko CA, Victoroff KZ, Wotman S. Comparison of patient perceptions of provider communication with observed data. JDR. Vol 87 Special issue. 2008; Toronto, Canada.

15. Ellingson M, Hamilton M, Demko CA. Patient attitudes toward general health discussions in the dental office. JDR. Vol 88 Special issue. 2009; Miami, FL.

16. Sudano J, Lalumandier J, Zyzanski S, Wotman S. Comparing sense of autonomy between dentists and physicians. JDR. 86 Special issue A. 2007; New Orleans.

17. American Dental Association. The 2005 survey of dental practice: income from the private practice of dentistry. Chicago, IL: American Dental Association; 2006.

18. Bailit H. Health services research. Adv Dent Res. 2003;17:82-85.

19. Zapka J, Stoddard A, Lubin H. A comparison of data from dental charts, client interview, and client mail survey. Med Care. 1988;26(1):27-33.

20. National Institutes of Dental and Craniofacial Research. Available from: http:/www.nidcr.nih.gov/Research/Extramural/ClinicalResearch/ GeneralPracticeBasedResearchNetworks.htmNIH networks.

21. Brennan D, Spencer A. The role of dentist, practice and patient factors in the provision of dental services. Community Dent Oral Epidemiol. 2005;33(3):181-195.

22. Gilbert G, Rose J, Shelton B. A prospective study of the validity of self-reported use of specific types of dental services. Public Health Rep. 2003;118(1):18-26.

23. Swedberg Y, Malmqvist J, Johnsson T. A method for dental care activities time study using observer monitored counting of frequencies. Swed Dent J. 1993;17(4):155-163.

24. Zapka J, Stoddard A, Lubin H. A comparison of data from dental charts, client interview, and client mail survey. Med Care. 1988;26(1):27-33.

25. Leake JL, Werneck RI. The use of administrative databases to assess oral health care. J Public Health Dent. 2005;65(1):21-35.
26. Bader J, Shugars D. Variation, treatment outcomes, and practice guidelines in dental practice. J Dent Educ. 1995;59(1):61-95.

27. Miller W, Crabtree F. Doing Qualitative Research. 2nd ed.

28. Snap Survey Software. Version 7. Boston, MA: SNAP Software; 2004.

29. SPSS Inc. SPSS. Version 13.0. Chicago, IL: SPSS Inc.; 2004.

30. STATA Corporation. Release 8. College Station, TX: STATA corporation; 2003.

31. Goodwin M. Using direct observation in primary care research- the Hawthorne effect: defining the nature and impact of the presence of research observers on patients and physicians in community family practice. [Dissertation]. Case Western Reserve University, Department of Epidemiology and Biostatistics) 2003.

32. American Dental Association. Survey of Dental Practice. Chicago, IL: American Dental Association; 2004.

33. American Dental Association. Employment of Dental Practice Personnel. Chicago, IL: American Dental Association; 2004.

34. Wotman S, Adelson R, Douglass C. Disaggregation of oral health care. A model for defining public and private responsibility. J Am Coll Dent. 1993;60(3):24-29.

35. US Census Bureau. Summary File 3 (SF 3). Available from http: //factfinder.census.gov. Generated by Joy Wiedemann using American Factfinder. Accessed 17 February 2006.

36. Brennan D, Spencer A, Szuster F. Dentist service rates and distribution of practice styles over time. Community Dent Oral Epidemiol. 1996;24(2):145-151.

37. Bertakis K, Helms L, Callahan E, Azari R, Robbins J. The influence of gender on physician practice style. Med Care. 1995;33(4):407-416.

38. Callahan E, Bertakis K. A comparison of physician-patient interaction at fee-for-service and HMO sites. Fam Pract Res J. 1993;13(2): $171-178$.

39. Frank S, Stange K, Langa D, Workings M. Direct observation of community-based ambulatory encounters involving medical students. JAMA. 1997;278(9):712-716. 


\section{Appendix}

\section{Dental doc}

Operational definitions for direct observation coding

CH Chatting: Dentist/hygienist or patient discussing topics not related to current visit, eg, small talk or humor which might be used to build rapport.

FL Family living ('Access to Care'): Any statement or discussion by dentist, hygienist or patient that includes a financial component related to oral health care. Discussion of finances linked to treatment decisions. Also includes any explicit discussion of a family situation that affects access to care or a treatment decision. For example, "My husband had surgery and that's why I haven't been in for a while." When discussion turns emotional or personal, the interaction should be coded CC.

CC Comfort: Dentist/hygienist discusses interpersonal relations or current emotional status of patient, provides reassurance, advice, or support, or uses self-disclosure to reassure patient; may also include dentist/hygienist reflecting on the patient's nonverbal behavior. Excludes asking for health behavior change (HP).

SI Structuring interaction: Dentist/hygienist or patient discussing what is to be done in current visit or dentist/ hygienist asks patient any questions. Excludes requests by dentist/hygienist to do anything which is part of the actual exam/treatment or is done to prepare the patient for the exam/treatment (DE). Excludes planning treatment (PT). Can include statements describing what will be done in oral exam/treatment.

HT History taking: Dentist/hygienist inquiring about or patient describing details related to the current chief complaint or to prior visits or treatment. Includes dentist reading dental record and patient response to current treatment. Includes dentist response to chief complaint and asking if exam maneuver produces pain or feeling described in chief complaint.

SH Systemic health: Dentist/hygienist inquiring or patient describing systemic health conditions or changes for patient. Excludes oral health (HT).

NE Negotiation: Dentist/hygienist comments, questions or invites patient participation in diagnosis, treatment planning, or problem-solving.

HK Health knowledge: Dentist/hygienist asks or patient spontaneously offers what patient knows or believes about health or disease. Excludes patient's own treatment history (HT).

EF Evaluation feedback: Dentist/hygienist tells patient about results of history, oral exam, biopsy, radiographs, etc.
Includes telling that information is incomplete or inconclusive or that results are preliminary or speculative.

DE Dental examination: Dentist/hygienist conducts any aspect of intraoral/extraoral examination of patient including interpreting radiographs, periodontal probing, or other diagnostic procedures; also includes asking patient to prepare for oral exam and/or telling patient to do something in oral exam.

OC Oral cancer screening: Dentist/hygienist conducts any aspect of an oral cancer screen/soft tissue exam, including face, lips, tongue, and other soft tissue oral structures.

LN Lymph node palpation: Dentist/hygienist palpates lymph nodes on head and neck.

PQ Patient question: Patient asks question of dentist/ hygienist about diagnosis, treatment, side effects, history of disease.

PR Procedure: Any treatment or diagnostic procedure done in the office. Excludes preventive services such as oral hygiene instruction, fluoride application, or mouthguard construction (OPP). Excludes cosmetic procedures which are coded CD. Includes oral prophylaxis.

CD Cosmetic dentistry: Any cosmetic treatment or diagnostic procedure done in office (eg, bleaching, veneers, bonding).

CM Compliance: Dentist/hygienist inquiring about or discussing what patient is currently doing or has done recently regarding previously requested behavior around oral hygiene, medication, changing nutrition, or other behavioral change. Double code with OPC, SM, NU, and SU.

OPC Oral preventive counseling: Dentist/hygienist provides counseling related to oral disease prevention or asks history on disease prevention. Includes oral hygiene instruction. Double code with HE, HP, CM. Excludes smoking, nutrition, and substance abuse counseling; these are coded separately as SM, NU, or SU.

OPP Oral preventive procedure: Dentist/hygienist discusses or performs any procedure associated with oral disease prevention. Includes topical fluoride application, sealants, mouthguard.

HE Health education: Dentist/hygienist presenting information regarding health to patient. This may include information regarding diagnosis, etiology, treatment effects, drug effects, and accident prevention. HE includes educating the patient about the need for a procedure. Also includes explanation of a procedure, its side effects, post-treatment effects or contraindications. Double code with OPC, SM, $\mathrm{NU}$, and SU.

HP Health promotion: Dentist/hygienist directing or asking for a change in patient's behavior in order to increase 
or promote patient health. Excludes explanation of the procedure itself, its side effects, post-treatment effects or contraindications (HE). Excludes asking a patient to take medication (PT). Double code with OPC, SM, NU, and SU.

PT Planning treatment: Dentist prescribes an oral diagnostic or treatment plan other than through behavioral change (HP). Includes describing treatment plan options.

SM Smoking behavior: Any question about or discussion of smoking or other tobacco use. Double code with HE, HP, CM.
NU Nutrition: Any question about or discussion of nutrition. Includes discussion of diet and/or food intake and any nutritional disorder. Double code with HE, HP, CM.

SU Substance use: Any question about or discussion of drinking alcohol or use of other substances (other than smoking). Double code with HE, HP, CM.

\section{Publish your work in this journal}

Clinical, Cosmetic and Investigational Dentistry is an international, peer-reviewed, open access, online journal focusing on the latest clinical and experimental research in dentistry with specific emphasis on cosmetic interventions. Innovative developments in dental materials, techniques and devices that improve outcomes and patient satisfac- tion and preference will be highlighted. The manuscript management system is completely online and includes a very quick and fair peerreview system, which is all easy to use. Visit http://www.dovepress. com/testimonials.php to read real quotes from published authors.

Submit your manuscript here: http://www.dovepress.com/clinical-cosmetic-and-investigational-dentistry-journal 